\title{
Free Vibration Analysis of an Un-cracked \& Cracked Fixed Beam
}

\author{
Malay Quila ${ }^{1}$, Prof. Samar Ch. Mondal ${ }^{2}$, Prof. Susenjit Sarkar ${ }^{3}$ \\ ${ }^{I}$ (P.G. Student, Department of Mechanical Engineering, Jadavpur University, India) \\ ${ }^{2,3}$ (Department of Mechanical Engineering, Jadavpur University, India)
}

\begin{abstract}
The presence of cracks causes changes in the physical properties of a structure which introduces flexibility, and thus reducing the stiffness of the structure with an inherent reduction in modal natural frequencies. Consequently it leads to the change in the dynamic response of the beam. This paper focuses on the theoretical analysis of transverse vibration of a fixed beam and investigates the mode shape frequency. All the theoretical values are analyzed with the numerical method by using ANSYS software and co relate the theoretical values with the numerical values to find out percentage error between them.Also in this paper, a model for free vibration analysis of a beam with an open edge crack has been presented. Variations of natural frequencies due to crack at various locations and with varying crack depths have been studied. A parametric study has been carried out. The analysis was performed using ANSYS software.
\end{abstract}

Keywords: Fixed beam, Free vibration, Mode Shape Natural Frequency, Crack, ANSYS.

\section{Introduction}

Most of the members of engineering structures operate under loading conditions, which may cause damages or cracks in overstressed zones. The presence of cracks in a structural member, such as a beam, causes local variations in stiffness, the magnitude of which mainly depends on the location and depth of the cracks. The presence of cracks causes changes in the physical properties of a structure which in turn alter its dynamic response characteristics. The monitoring of the changes in the response parameters of a structure has been widely used for the assessment of structural integrity, performance and safety. Irregular variations in the measured vibration response characteristics have been observed depending upon whether the crack is closed, open or breathing during vibration.

The vibration behavior of cracked structures has been investigated by many researchers. The majority of published studies assume that the crack in a structural member always remains open during vibration. However, this assumption may not be valid when dynamic loadings are dominant. In such case, the crack breathes (opens and closes) regularly during vibration, inducing variations in the structural stiffness. These variations cause the structure to exhibit non-linear dynamic behavior. Christides and Barr [1] developed a onedimensional cracked beam theory at same level of approximation as Bernoulli-Euler beam theory. Liang, Choy and Jialou $\mathrm{Hu}$ [3] presented an improved method of utilizing the weightless torsional spring model to determine the crack location and magnitude in a beam structure. Dimaragonas [4] presented a review on the topic of vibration of cracked structures. His review contains vibration of cracked rotors, bars, beams, plates, pipes, blades and shells. Shen and Chu [5] and Chati, Rand and Mukherjee [6] extended the cracked beam theory to account for opening and closing of the crack, the so called "breathing crack" model. Kisa and Brandon [7] used a bilinear stiffness model for taking into account the stiffness changes of a cracked beam in the crack location.

They have introduced a contact stiffness matrix in their finite element model for the simulation of the effect of the crack closure which was added to the initial stiffness matrix at the crack location in a half period of the beam vibration. Saavedra and Cuitino [8] and Chondros, Dimarogonas and Yao [9] evaluated the additional flexibility that the crack generates in its vicinity using fracture mechanics theory. Zheng et al [10] the natural frequencies and mode shapes of a cracked beam are obtained using the finite element method. An overall additional flexibility matrix, instead of the local additional flexibility matrix, is added to the flexibility matrix of the corresponding intact beam element to obtain the total flexibility matrix, and therefore the stiffness matrix. Zsolt huszar [11] presented the quasi periodic opening and closings of cracks were analyzed for vibrating reinforced concrete beams by laboratory experiments and by numeric simulation. The linear analysis supplied lower and upper bounds for the natural frequencies. Owolabi, Swamidas and Seshadri [12] carried out experiments to detect the presence of crack in beams, and determine its location and size. Behzad, Ebrahimi and Meghdari [14] developed a continuous model for flexural vibration of beams with an edge crack perpendicular to the neutral plane. The model assumes that the displacement field is a superposition of the classical EulerBernoulli beam's displacement and of a displacement due to the crack. Shifrin [16] presented a new technique is proposed for calculating natural frequencies of a vibrating beam with an arbitrary finite number of transverse open cracks. Most of the researchers studied the effect of single crack on the dynamics of the structure. A local flexibility will reduce the stiffness of a structural member, thus reducing its natural frequency. Thus most popular parameter applied in identification methods is change in natural frequencies of structure caused by the 
crack. In this paper, the natural frequencies of cracked and un-cracked beams have been calculated using Finite element software ANSYS and up to fifth mode natural frequency graph is presented.

\section{Theoretical Analysis Of Transverse Vibration Of Fixed Beam}

A beam which is fixed at both ends is known as fixed beam. From elementary theory of bending of beams also known as Euler-Bernoulli, the relationship between the bending moment and deflection can be expressed as;

$$
\mathrm{M}=\mathrm{EI} \frac{d^{2} y}{d x^{2}}
$$

Where, E is Young's Modulus and I is the moment of inertia of the beam c/s. For uniform beam we can obtain equation of motion as;

$$
\frac{E I}{\rho A} \frac{d^{4} y}{d x^{4}}+\frac{d^{2} y}{d t^{2}}=0
$$

Where, $\rho$ is the mass density and $\mathrm{A}$ is the cross sectional area of the beam.

Where $\mathrm{c}=\sqrt{\frac{E I}{\rho A}}$

$$
c^{2} \frac{d^{4} y}{d x^{4}}+\frac{d^{2} y}{d t^{2}}=0
$$

The solution of equation (2) depends on position and another on time

So, the solution is $\mathrm{y}=\mathrm{w}(\mathrm{x}) \mathrm{T}(\mathrm{t})$

By substituting Eq. (3) to Eq. (2) and simplifying it we get;

$$
\frac{c^{2}}{w(x)} \frac{d^{4} w(x)}{d x^{4}}=-\frac{1}{T(t)} \frac{d^{2} T(t)}{d t^{2}}
$$

The Eq. (4) can be written as two separate differential equations;

$$
\begin{aligned}
& \frac{d^{4} w}{d x^{4}}-\beta^{4} w(x)=0 \\
& \frac{d^{2} T(t)}{d t^{2}}+\omega^{2} T(t)=0
\end{aligned}
$$

Where, $\beta^{4}=\frac{\omega \mathrm{i}^{2}}{c^{2}}=\frac{\rho A \omega \mathrm{i}^{2}}{E I}$

To find out the solution of (5) Considering the equation;

$\mathrm{w}(\mathrm{x})=\mathrm{C}_{1} \cosh \beta(x)+\mathrm{C}_{2} \sinh \beta(x)+\mathrm{C}_{3} \cos \beta(x)+\mathrm{C}_{4} \sin \beta(\mathrm{x})$

In order to solve Eq.(6) the following boundary conditions for the fixed beam are needed;

At $\mathrm{x}=0 \mathrm{w}(\mathrm{x})=0, \frac{d w}{d x}=0$

At $\mathrm{x}=\mathrm{L} w(\mathrm{x})=0, \frac{d w}{d x}=0$

Now using the expression for mode shape (Eq.6) and applying the boundary conditions following relations can be obtained:

$\mathrm{w}(\mathrm{x})=\mathrm{C}_{1} \cosh \beta(x)+\mathrm{C}_{2} \sinh \beta(x)+\mathrm{C}_{3} \cos \beta(x)+\mathrm{C}_{4} \sin \beta(\mathrm{x})$

$\begin{array}{ll}\text { At } \mathrm{w}(0)=0, & C_{1}+C_{3}=0 \\ \text { At } \mathrm{w}(\mathrm{L})=0, & C_{1} \cosh \beta L+C_{2} \sinh \beta L+C_{3} \cos \beta L+C_{4} \sin \beta L=0\end{array}$

$C_{2}+C_{4}=0$

At $w^{\prime}(L)=0$

$C_{1} \sinh \beta L+C_{2} \cosh \beta L-C_{3} \sin \beta L+C_{4} \cos \beta L=0$

From Eq.(7) $\quad C_{3}=-C_{1}$

From Eq.(9) $\quad C_{4}=-C_{2}$

From Eq.(8) we get $C_{1} \cosh \beta L+C_{2} \sinh \beta L-C_{1} \cos \beta L-C_{2} \sin \beta L=0$

From Eq.(10) we get $\quad C_{1} \sinh \beta L+C_{2} \cosh \beta L+C_{1} \sin \beta L-C_{2} \cos \beta L=0$

From Eq.(11) we get $\frac{C_{1}}{C_{2}}=\frac{(\sin \beta L-\sinh \beta L)}{(\cosh \beta L-\cos \beta L)}$

From Eq.(12) we get $\frac{C_{1}}{C_{2}}=\frac{(\cos \beta L-\cosh \beta L)}{(\sinh \beta L+\sin \beta L)}$

Hence $\frac{(\sin \beta L-\sinh \beta L)}{(\cosh \beta L-\cos \beta L)}=\frac{(\cos \beta L-\cosh \beta L)}{(\sinh \beta L+\sin \beta L)}$

and finally we get $\cosh \beta L \cos \beta L=1$

This transcendental equation has an infinite number of solution $\beta_{i}=1,2,3 \ldots \mathrm{n}$

Corresponding giving an infinite number of frequencies,

Hence $\omega_{\mathrm{i}}=\left(\beta_{\mathrm{i}} \mathrm{L}\right)^{2} \sqrt{\frac{E I}{\rho A L^{4}}}$ 
The first five roots of the Eq. (7) are shown in TABLE-1.

Table-1 Value of Roots

\begin{tabular}{|c|c|}
\hline Roots (i) & $\beta_{i} \mathrm{~L}$ \\
\hline 1 & 4.730 \\
\hline 2 & 7.853 \\
\hline 3 & 10.996 \\
\hline 4 & 14.137 \\
\hline 5 & 17.278 \\
\hline
\end{tabular}

The dimensions and the material constant for the uniform fixed beam investigated in this paper are: Material of beam $=$ Steel, Total length $(\mathrm{L})=0.5 \mathrm{~m}$, Width $(\mathrm{b})=0.045 \mathrm{~m}$, Height $(\mathrm{h})=0.005 \mathrm{~m}$, Moment of $\operatorname{inertia}(\mathrm{I})=4.6875 \times 10^{-10} \mathrm{~m}^{4}$, Young Modulus $(\mathrm{E})=200 \mathrm{Gpa}$, Mass per unit length $(\mathrm{M})=0.30375 \mathrm{~kg}$, Density $=7800 \mathrm{~kg} / \mathrm{m}^{3}$.Poisson's ratio $=0.3$

Putting all required data in Eq.(7)the five frequencies obtained are shown in TABLE-2.

Table-2 Mode Shape Frequency $(\mathrm{Hz})$

\begin{tabular}{|c|c|}
\hline Mode & Frequency in $\mathrm{Hz}$ \\
\hline 1 & 104.099 \\
\hline 2 & 286.944 \\
\hline 3 & 562.596 \\
\hline 4 & 929.911 \\
\hline 5 & 1389.00 \\
\hline
\end{tabular}

The numerical results found out by using the ANSYS program as shown in TABLE-3.

Table-3 Mode Shape Frequency using ANSYS (Hz)

\begin{tabular}{|c|c|}
\hline Mode & Frequency in $\mathrm{Hz}$ \\
\hline 1 & 105.39 \\
\hline 2 & 290.28 \\
\hline 3 & 568.77 \\
\hline 4 & 939.89 \\
\hline 5 & 1403.60 \\
\hline
\end{tabular}

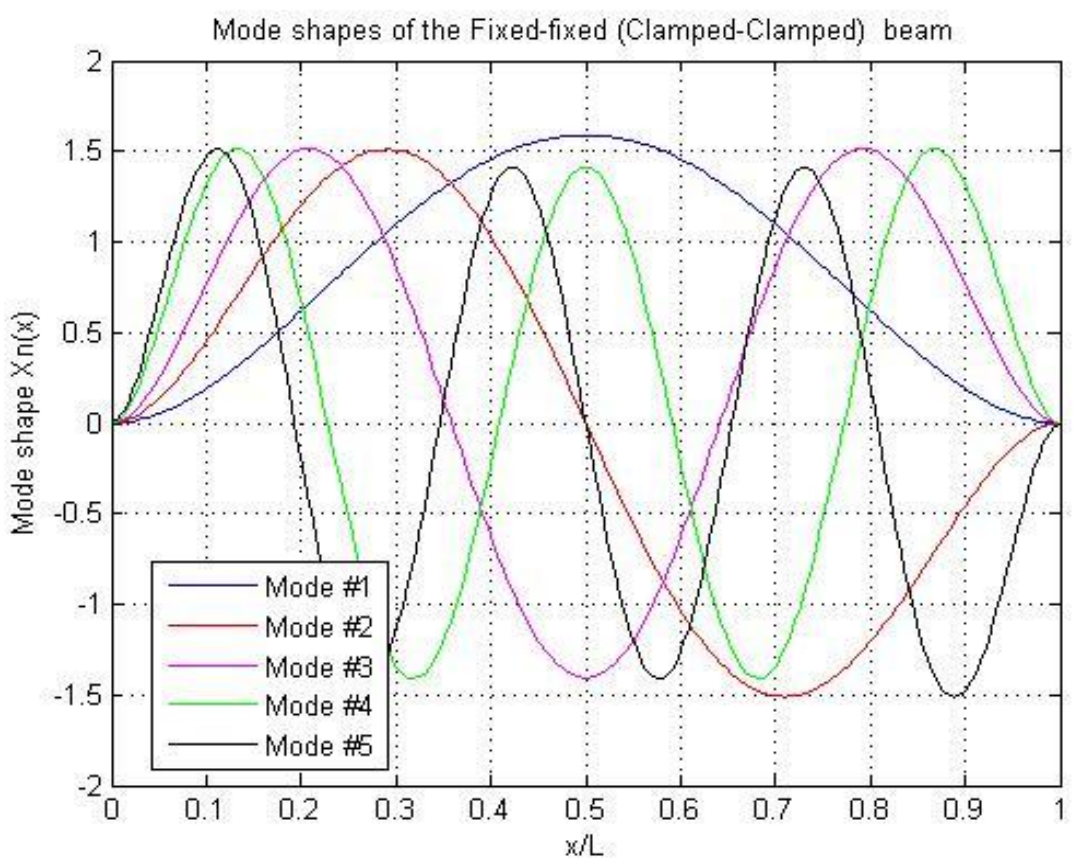


The mode shapes of free vibration of the fixed beam are shown in Fig1.
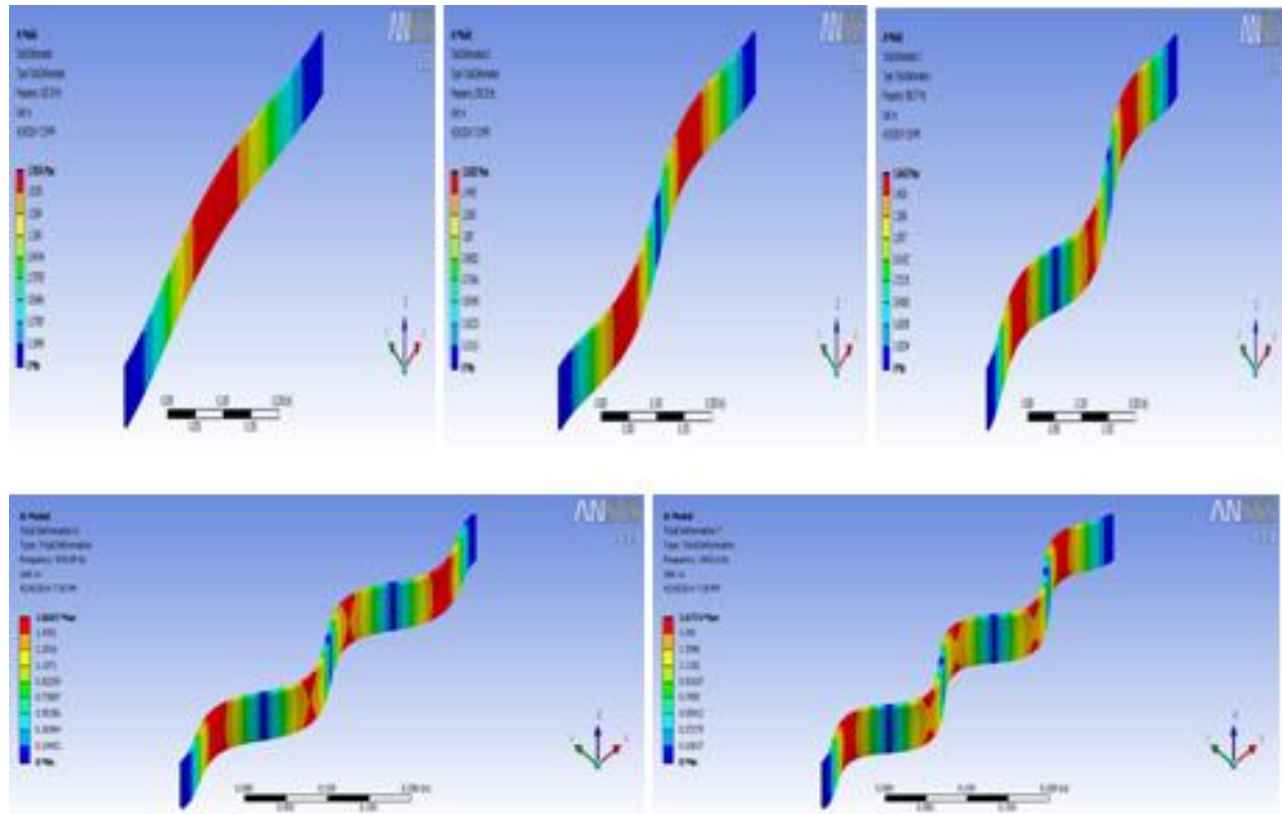

Fig. 1 mode shapes of free vibration of the fixed beam

The percentage error between theoretical and numerical result are shown in TABLE-4.

Table-4 Percentage Error (\%)

\begin{tabular}{|c|c|c|c|}
\hline Mode & Theoretical frequency in $\mathrm{Hz}$ & Numerical frequency from ANSYS program in Hz & Percentage Error (\%) \\
\hline 1 & 104.099 & 105.39 & 1.20 \\
\hline 2 & 286.944 & 290.28 & 1.15 \\
\hline 3 & 562.596 & 568.77 & 1.08 \\
\hline 4 & 929.911 & 939.89 & 1.06 \\
\hline 5 & 1389.00 & 1403.60 & 1.04 \\
\hline
\end{tabular}

\section{Crack Modeling}

Cracks in the beam create changes in geometrical properties so it becomes complex to study the effect of cracks in the beam. The crack modeling has been very important aspect. The analysis has been done using finite element method. FEM software package ANSYS has been used. Cracked beam has been modeled and free vibration analysis has been performed considering geometric and material non linearity. The crack is considered to be an open edge notch. Crack with a $0.5 \mathrm{~mm}$ width on the top surface of the beam has been modeled. It is assumed that crack have uniform depth across the width of the beam.

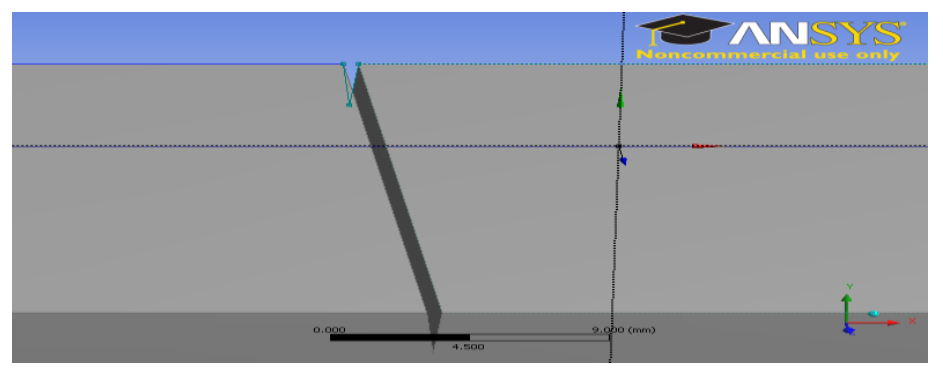

Fig.2 V-shaped edge crack with a $0.5 \mathrm{~mm}$ width on the top surface of the beam 


\section{Parametric Studies Of The Fixed Beam}

The effects of the crack on natural frequency of a fixed steel beam were investigated for various crack depths and crack locations

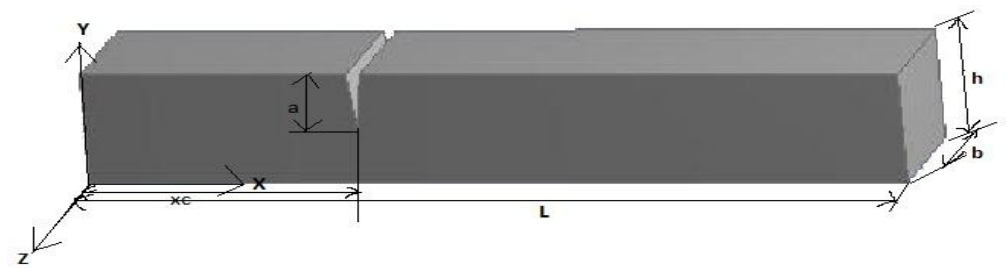

Properties:

Fig.3 fixed beam with a crack

Width of the beam $=0.045 \mathrm{~m}$, Depth of the beam $=0.005 \mathrm{~m}$, Length of the beam $=0.5 \mathrm{~m}$, Elastic modulus of the beam $(\mathrm{E})=200 \mathrm{GPa}$, Poisson's Ratio $=0.3$, Density $=7800 \mathrm{~kg} / \mathrm{m}^{3}$

Natural frequencies of the fixed beam for the first, second, third, fourth and fifth modes of vibration have been studied. For simplicity, the following dimensionless quantities are introduced:

Crack location ratio $\zeta_{c}=\left(x_{c} / \mathrm{L}\right)$

Crack depth ratio $\mathrm{H}=(\mathrm{a} / \mathrm{h})$

Table-5 Natural frequency of the fixed beam with a crack for the first mode:- $\omega=105.39 \mathrm{~Hz}$

\begin{tabular}{|c|c|c|}
\hline Crack position $\zeta_{c}=\left(x_{c} / \mathrm{L}\right)$ & Crack depth ratio $\mathrm{H}=(\mathrm{a} / \mathrm{h})$ & Natural frequency ratio $\left(\omega_{c} / \omega\right)$ \\
\hline \multicolumn{2}{|c|}{ Un-cracked beam } & 1.0000 \\
\hline \multirow{3}{*}{0.2} & 0.1 & 1.0000 \\
\cline { 2 - 3 } & 0.3 & 0.9999 \\
\cline { 2 - 3 } & 0.5 & 0.9995 \\
\hline \multirow{3}{*}{0.3} & 0.1 & 1.0000 \\
\cline { 2 - 3 } & 0.3 & 0.9990 \\
\cline { 2 - 3 } & 0.5 & 0.9960 \\
\hline \multirow{2}{*}{0.5} & 0.1 & 0.9995 \\
\cline { 2 - 3 } & 0.3 & 0.9952 \\
\cline { 2 - 3 } & 0.5 & 0.9831 \\
\hline
\end{tabular}

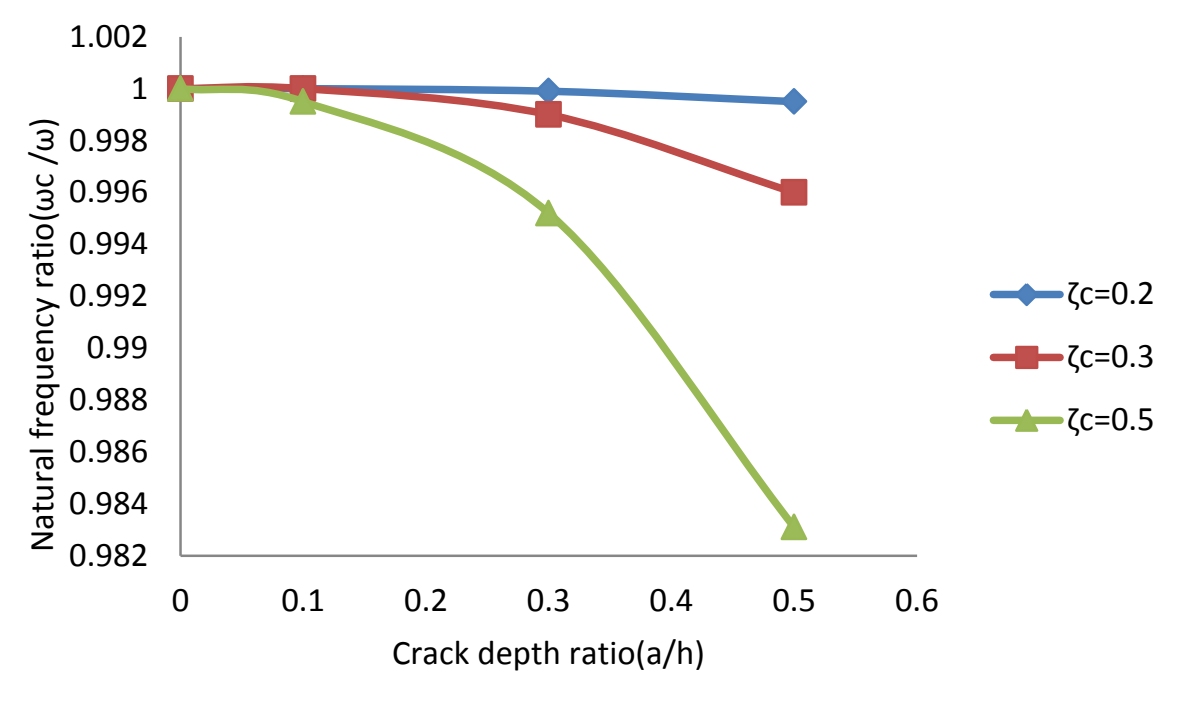

Fig.4 Natural frequency of the fixed beam with a crack for the first mode 
Table-6 Natural frequency of the fixed beam with a crack for the second mode: $\omega=290.28 \mathrm{~Hz}$

\begin{tabular}{|c|c|c|}
\hline Crack position $\zeta_{c}=\left(x_{c} / \mathrm{L}\right)$ & Crack depth ratio $\mathrm{H}=(\mathrm{a} / \mathrm{h})$ & Natural frequency ratio $\left(\omega_{c} / \omega\right)$ \\
\hline \multicolumn{2}{|c|}{ Un-cracked beam } & 1.000 \\
\hline \multirow{3}{*}{0.2} & 0.1 & 0.9998 \\
\cline { 2 - 3 } & 0.3 & 0.9977 \\
\cline { 2 - 3 } & 0.5 & 0.9927 \\
\hline \multirow{3}{*}{0.3} & 0.1 & 0.9996 \\
\cline { 2 - 3 } & 0.3 & 0.9939 \\
\cline { 2 - 3 } & 0.5 & 0.9793 \\
\hline \multirow{3}{*}{0.5} & 0.1 & 0.9999 \\
\cline { 2 - 3 } & 0.3 & 0.9998 \\
\cline { 2 - 3 } & 0.5 & 0.9998 \\
\hline
\end{tabular}

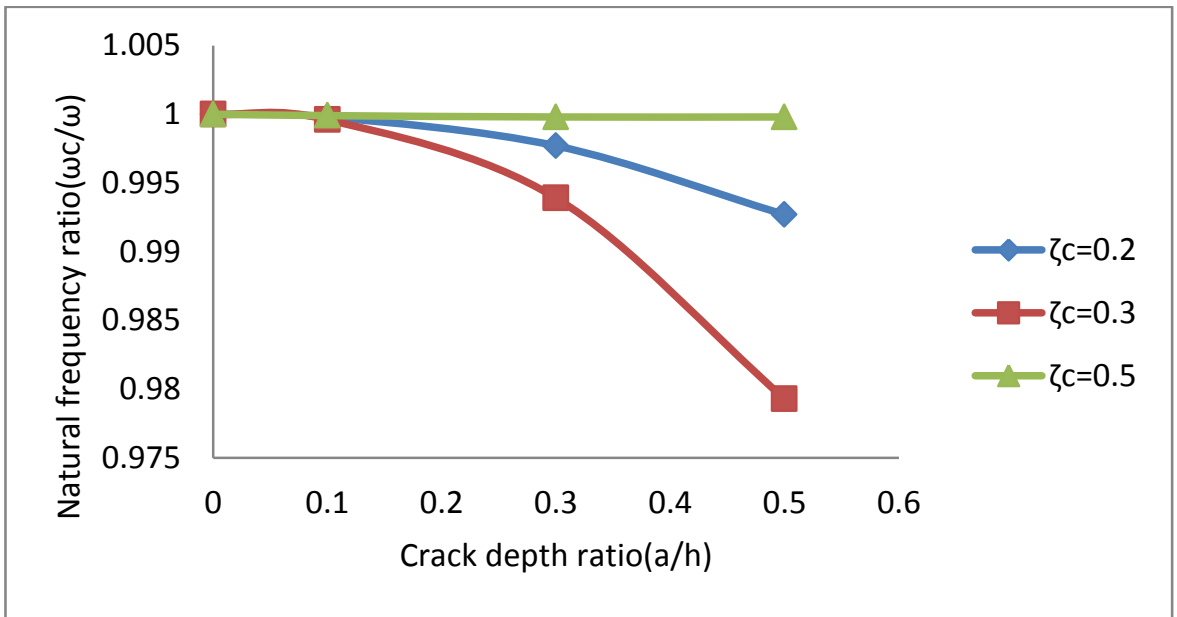

Fig.5 Natural frequency of the fixed beam with a crack for the second mode

Table-7 Natural frequency of the fixed beam with a crack for the third mode: $\omega=568.77 \mathrm{~Hz}$

\begin{tabular}{|c|c|c|}
\hline Crack position $\zeta_{c}=\left(x_{c} / \mathrm{L}\right)$ & Crack depth ratio $\mathrm{H}=(\mathrm{a} / \mathrm{h})$ & Natural frequency ratio $\left(\omega_{c} / \omega\right)$ \\
\hline \multicolumn{2}{|c|}{ Un-cracked beam } & 1.000 \\
\hline \multirow[t]{3}{*}{0.2} & 0.1 & 0.9995 \\
\hline & 0.3 & 0.9943 \\
\hline & 0.5 & 0.9811 \\
\hline \multirow[t]{3}{*}{0.3} & 0.1 & 0.9998 \\
\hline & 0.3 & 0.9975 \\
\hline & 0.5 & 0.9924 \\
\hline \multirow[t]{3}{*}{0.5} & 0.1 & 0.9992 \\
\hline & 0.3 & 0.9934 \\
\hline & 0.5 & 0.9774 \\
\hline
\end{tabular}

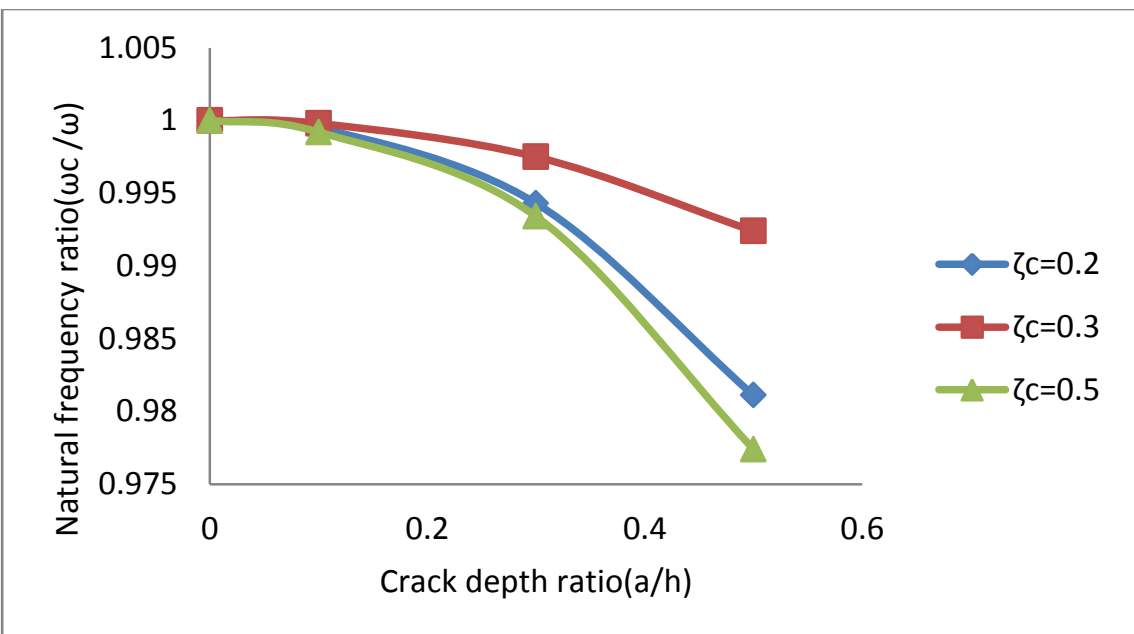

Fig.6 Natural frequency of the fixed beam with a crack for the third mode 
Table-8 Natural frequency of a fixed beam with a crack for the fourth mode: $-\omega=939.89 \mathrm{~Hz}$

\begin{tabular}{|c|c|c|}
\hline Crack position $\zeta_{c}=\left(x_{c} / \mathrm{L}\right)$ & Crack depth ratio $\mathrm{H}=(\mathrm{a} / \mathrm{h})$ & Natural frequency ratio $\left(\omega_{c} / \omega\right)$ \\
\hline \multicolumn{2}{|c|}{ Un-cracked beam } & 1.000 \\
\hline \multirow{3}{*}{0.2} & 0.1 & 0.9996 \\
\hline & 0.3 & 0.9944 \\
\hline & 0.5 & 0.9839 \\
\hline \multirow{3}{*}{0.3} & 0.1 & 0.9998 \\
\hline & 0.3 & 0.9988 \\
\hline & 0.5 & 0.9974 \\
\hline \multirow{3}{*}{0.5} & 0.1 & 0.9999 \\
\hline & 0.3 & 0.9996 \\
\hline & 0.5 & 0.9997 \\
\hline
\end{tabular}

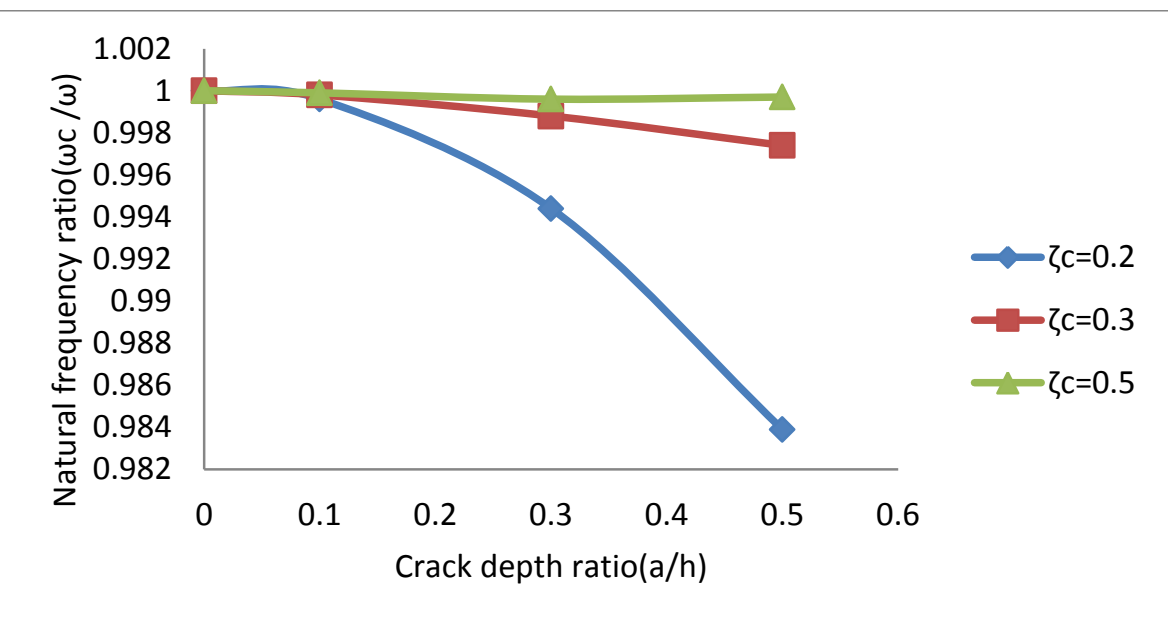

Fig.7 Natural frequency of a fixed beam with a crack for the fourth mode

Table-9 Natural frequency of a fixed beam with a crack for the fifth mode: $-\omega=1403.60 \mathrm{~Hz}$

\begin{tabular}{|c|c|c|}
\hline Crack position $\zeta_{c}=\left(x_{c} / \mathrm{L}\right)$ & Crack depth ratio $\mathrm{H}=(\mathrm{a} / \mathrm{h})$ & Natural frequency ratio $\left(\omega_{c} / \mathrm{\omega}\right)$ \\
\hline \multirow{3}{*}{0.2} & Un-cracked beam & 1.000 \\
\hline \multirow{3}{*}{0.3} & 0.1 & 0.9998 \\
\cline { 2 - 3 } & 0.3 & 0.9977 \\
\cline { 2 - 3 } & 0.5 & 0.9953 \\
\cline { 2 - 3 } & 0.1 & 0.9995 \\
\cline { 2 - 3 } & 0.3 & 0.9957 \\
\hline \multirow{3}{*}{0.5} & 0.5 & 0.9789 \\
\cline { 2 - 3 } & 0.1 & 0.9992 \\
\cline { 2 - 3 } & 0.3 & 0.9932 \\
\hline
\end{tabular}

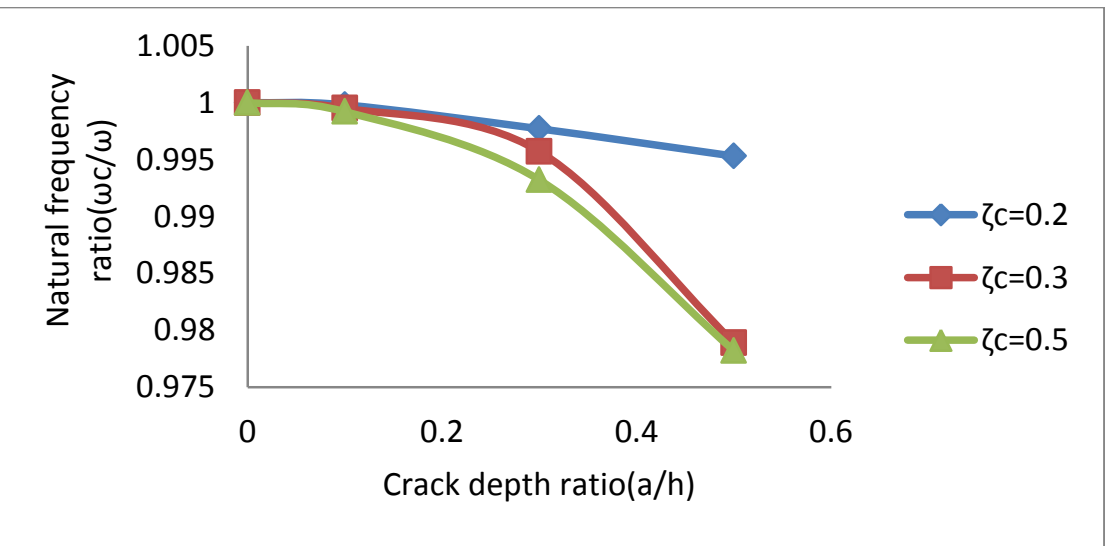

Fig.8 Natural frequency of a fixed beam with a crack for the fifth mode 


\section{Observations}

Fig. 4, Fig. 5, Fig.6, Fig.7and Fig.8 show the ratio of natural frequencies of the fixed beam with a single edge crack at various crack locations and crack depths for first, second, third, fourth and fifth modes of vibration respectively. Results show that there is an appreciable variation between natural frequency of cracked and un-cracked fixed beam. When the position of the crack is at that point where amplitude of vibration is zero there is no change in natural frequency in spite of change in crack depth. Natural frequency changes drastically when crack is on that point where amplitude of vibration is maximum. It is observed that natural frequency of the cracked beam decreases both with increase in crack distance and crack depth due to reduction in stiffness. It appears therefore that the change in frequencies is not only a function of crack depth and crack location but also of the mode number.

\section{Conclusion}

- It has been observed that the natural frequency changes substantially due to the presence of cracks depending upon location and size of cracks

- When the crack positions are constant i.e. at particular crack location, the natural frequencies of a cracked beam are inversely proportional to the crack depth

- It has been observed that the change in frequencies is not only a function of crack depth, and crack location, but also of the mode number

- As largest effects are observed at the centre for fixed beam we can say, decrease in frequencies is more for a crack located where the bending moment is higher.

\section{Acknowledgement}

I have many to thank for successfully getting this far. By far the most important is Prof. Susenjit Sarkar who continually encouraged me to pursue my passions. Further, I thank Dr. Samar Ch. Mondal for his dedication towards my research.

\section{References}

[1]. J.P. Chopade , R.B. Barjibhe, journal of Free Vibration Analysis of Fixed Free Beam with Theoretical and Numerical Approach Method (Vol. 2 Issue 1 February 2013).

[2]. Gawali A.L. and Sanjay C. Kumawat, journals of Vibration Analysis of Beams (Volume 1, Issue 1, 2011)

[3]. Papadopoulos C.A., Dimarogonas A.D. (1987) Journal of Sound and Vibration, 117(1), 81-93.

[4]. Zheng D.Y., Fan S.C. (2003) Journal of sound and vibration, 267, 933-954.

[5]. Christides S., Barr A.D.S. (1984) Journal of mechanical science, 26(11/12), 639-648.

[6]. Shen M.H.H., Pierre C. (1990) Journal of sound and vibration, 138(1), 115-134.

[7]. Shen M.H.H., Pierre C. (1994) Journal of sound and vibration, 170(2), 237-259.

[8]. Kocat urk T., S, ims, ek M. (2005) Sigma J. Eng. and Nat. Sci. 1, 108-122.

[9]. Kocat"urk T., S, ims ek M. (2005) Sigma J. Eng. and Nat. Sci., 3, 79-93.

[10]. Lee J., Schultz W.W. (2004) J. Sound Vib., 269, 609-621

[11]. S.Christides, A.D.S. Barr. "One- dimensional theory of cracked Bernoulli-Euler beam." Journal of Mechanical Science 26, 1984: 639-648. .

[12]. Robert Liang, Fred K. Choy, Jialou Hu. "Detection of cracks in beam structure using measurment of natural frequencies." Journal of the Franklin Institute, Vol.328, 1991: 505-518.

[13]. D.Dimarogonas, Andrew. "Vibration of cracked structures: Astate of the art review." Engineering Fracture Mechanics, Vol.55, 1996: 831-857.

[14]. [M. H. H. Shen, Y. C. Chu. "Vibration of beams with fatigue cracks." Computers and Structures 45, 1992: $79-93$.

[15]. M. Chati, R. Rand, S. Mukherjee. "Modal analysis of cracked beam." Journal of Sound and Vibration 207, 1997: 249-270.

[16]. M. Kisa, B. Brandon. "The effects of closure of cracks on the dynamics of cracked cantilever beam." Journal of Sound and Vibration, 238(1), 2000: 1-18.

[17]. P.N. Saavedra, L.A.Cuitino. "Crack detection and vibration behavior of cracked beams." Computers and Structures 79, 2001: 14511459.

[18]. T. G. Chondros, A. D. Dimorogonas, J. Yao. "Vibration of a beam with a breathing crack." Journal of Sound and Vibration 239(1), 2001: 57-67.

[19]. D.Y. Zheng. "Free Vibration Analysis Of A Cracked Beam By finite Element Method." Journal of Sound and Vibration, 2004: 457475

[20]. D.Y. Zheng. "Free Vibration Analysis Of A Cracked Beam By finite Element Method." Journal of Sound and Vibration, 2004: 457475 .

[21]. Huszar, Zsolt. "Vibration of cracked reinforced and prestressed concrete beams Architecture and Civil Engineering, Vol. 6, 2008: $155-164$

[22]. G.M.Owolabi, Swamidas, SeshadrI " Crack detection in beams using changes in frequencies and amplitudes of frequency response functions." Journal of Sound and Vibration, 265(2004) 1-22

[23]. M.Behzad, Ebrahimi, A.Meghdari. "A continuous vibration theory for beams with a vertical edge crack." Mechanical Engineering, Vol. 17, 2010: 194-204.

[24]. E. I. Shifrin. "Natural Frequencies Of A Beam With An Arbitrary Number Of Cracks." Journal of Sound and Vibration, 222(3), 1999: 409-423 